\title{
The influence of culture and transparency on global research and development intensity: An overview across Europe
}

\author{
La influencia de la cultura y transparencia en la intensidad global \\ de investigación y desarrollo: una visión general en Europa \\ Ilídio Tomás Lopes* ${ }^{*}$ Rogério Marques Serrasqueiro \\ Instituto Universitário de Lisboa, Business Research Unit, Portugal
}

Received 8 June 2016; accepted 2 December 2016

Available online 5 July 2017

\begin{abstract}
Culture and transparency can be described as a set of beliefs, norms, and actions, which drive the human action into innovativeness. Over the centuries, those pillars have driven individuals, groups, organizations, and nations, into the most complex networking schemes. It seems now unquestionable that those beliefs and policies, affect both private and public organizations, driving them across innovation wages in a more incremental or radical way. The dependent variable in this research $(R \& D)$ embodies the disbursements in research and development, carried out by business enterprise and public sector, and by education institutions. Thus, this research aims to mainly explore the effect of culture and transparency, as drivers of business attractiveness, on global R\&D intensity. Using information from 31 European countries over the period 2010-2014, total R\&D expenditures were regressed against several variables such as the Hofstede's cultural dimensions, the public sector transparency index, and other aggregated variables. Most of the theoretical assumptions are now supported by our empirical outcomes. Culture and transparency can act as attractiveness drivers,
\end{abstract}

\footnotetext{
* Corresponding author.

E-mail address: Ilidio.Tomas.Lopes@ iscte.pt (I.T. Lopes).
}

Peer Review under the responsibility of Universidad Nacional Autónoma de México. 
for business sector organizations and for other private and public institutions, toward the implementation of knowledge transformation mechanisms and intellectual capital achievements.

(C) 2017 Universidad Nacional Autónoma de México, Facultad de Contaduría y Administración. This is an open access article under the CC BY-NC-ND license (http://creativecommons.org/licenses/by-nc-nd/4.0/).

JEL classification: M21; M40

Keywords: Knowledge; Innovation; Research and development; Culture; Transparency; Europe

\section{Resumen}

La cultura y la transparencia se pueden describir como un conjunto de creencias, normas y acciones que impulsan la acción humana en su capacidad de innovación. En los últimos siglos, cultura y transparencia han impulsado los individuos, grupos, organizaciones y naciones en la implementación de redes más complejas. Parece actualmente incuestionable que las creencias y políticas afectan a las organizaciones privadas y públicas, llevando a implementar mecanismos de innovación de forma radical. La variable dependiente (I\&D) agrupa los desembolsos en investigación y desarrollo llevados a cabo por las empresas, por el sector público y por las instituciones educativas. Por lo tanto, la presente investigación tiene como objetivo primario estudiar el efecto de la cultura y de la transparencia en la intensidad global de I\&D. Utilizando la información de 31 países europeos durante el período 2010-2014, el total de gastos en I\&D se ha correlacionado con diversas variables, como por ejemplo las dimensiones culturales de Hofstede, el índice de transparencia del sector público y otras variables agregadas. La mayor parte de las evidencias teóricas son, en esta investigación, soportadas por los resultados empíricos de manera significativa. Por lo tanto, solo las economías que están orientadas a la transformación del conocimiento y están comprometidas con la producción de capital intelectual incluyen en su estrategia una fuerte inversión en investigación y desarrollo.

(C) 2017 Universidad Nacional Autónoma de México, Facultad de Contaduría y Administración. Este es un artículo Open Access bajo la licencia CC BY-NC-ND (http://creativecommons.org/licenses/by-nc-nd/4.0/).

Códigos JEL: M21; M40

Palabras clave: Conocimiento; Innovación; Investigación y desarrollo; Cultura; Transparencia; Europa

\section{Introduction and research objective}

Innovation derives from the Latin innovatio and embodies an action or process of innovating. It is associated to changes, with a certain level of novelty, by introducing new methods, ideas, or products. It translates the ability to produce knowledge, it contributes to potential inflows, and it is widely recognized as one of the primary driving forces of growth and profitability. Over the last decades, researchers tried to identify the sources that drive individuals and organizations to innovate and contribute to value creation and sustainable development across firms and nations (Chen, Hu, \& Yang, 2011; Deschryvere, 2014; Fontana, Nuvolary, Shimizy, \& Vezzulli, 2012; Jewkes, Sawers, \& Stillerman, 1958; Malerba \& Orsenigo, 1995, Malerba \& Orsenigo, 1996; Pavitt, 1984; VanderPal, 2015). In these different approaches toward the identification of innovation drivers, Schumpeterian patterns have been stated as the most robust findings across the literature. Thus, innovative activities differ across industries along several dimensions, in particular the knowledge intensity embedded in those activities, the type of actors and institutions involved in innovative activities and innovation policies, and the economic effects of innovations (Fernández-Jardón, Costa, \& Dorregio, 2014; Malerba, 2005). Those patterns are structured around four dimensions: 1 , concentration and asymmetries among innovating firms in each particular sector; 2 , size of the innovating firms; 3 , changes over time in the hierarchy of innovators; 4 , relevance of the entry 
of new innovators. Fontana et al. (2012) explore the most recent literature about Schumpeterian patterns of innovation and contribute to identify the sources of breakthrough inventions by extracting new outcomes on the base of the mentioned old patterns. Broadly, a turbulent environment rather than a more stable is conducive to a higher probability of the occurrence of breakthrough inventions.

Research and Development $(R \& D)$ is probably the most known and used proxy to measure the innovation intensity across entities and nations. According to International Accounting 38 (IFRF, 2004), "Research" relates to the original and planned investigation undertaken with the prospect of gaining new scientific or technical knowledge and understanding while "Development" is the application of research findings or other knowledge to a plan or design, for the production of new or substantially improved materials, devices, products, processes, systems, or services prior to commencement of commercial production or use. Thus, R\&D expenditures could lead entities (public and private) into growth, into increased returns, and into subsequently financial and strategic achievements. These knowledge based expenditures are the basis of innovation, driving companies to potential economic benefits (Fernández-Jardón et al., 2014; Tahinakis \& Samarinas, 2013; VanderPal, 2015). According to Chen et al. (2011), most nations have gradually devoted more efforts on $\mathrm{R} \& \mathrm{D}$, and have tried to create a favorable innovation environment by enforcing intellectual property rights to promote innovations. At a microeconomic level, literature does not provide unanimous evidence about the relationship between innovation and turnover (Chan, Lokoniskok, \& Sougiannis, 2003; Deschryvere, 2014; Lev \& Sougiannis, 1996; VanderPal, 2015). Deschryvere (2014) found that large firms that are continuous innovators have significant positive two-way associations between R\&D growth and sales growth; however, in small continuous product innovators that association is clearly stronger than for large ones. Furthermore, relating the occasional process and product innovators, he found a positive and significant association between sales growth and subsequent R\&D growth. However, Chan et al. (2003) do not support a direct relationship between $R \& D$ expenditures and future returns, in the scope of the stock market valuation derived from R\&D expenditures. Different evidences were obtained by Lev and Sougiannis (1996) relating insider gains. These gains in R\&D inside intensive companies are significantly higher than insider gains obtained in firms not strongly engaged in innovation expenditures. Although the complex relationships between R\&D and subsequent economic benefits, if efficiently and productively used, R\&D can serve as a major source of competitive advantage (Chen et al., 2011). According to Akinwale, Dada, Oluwadare, and Jesuleye (2012), it is not enough to increase the expenditures on R\&D and innovation when countries have weak institutions and networks, and poor coordination systems. Building a creative high performance R\&D culture is required. This creative culture combines customer focus, risk tolerance, entrepreneurship, alignment with strategies, innovation, virtual organization and networking, and efficient execution. Building a creative winning $R \& D$ culture is embedded on values, expertise, short and long term orientation, and effective policies. Thus, national culture, as a driver of attractiveness for individuals and organizations, is probably the most critical driver of the aggregated (at a macro and microeconomic levels) innovation effectiveness, also embodied on macroeconomic variables such as gross domestic product, on high technology trade, on human resources in science and on technology, venture capital investments, among others (Ambos \& Schlegelmilch, 2008; Newman, 2009; Skerlavaj, Su, \& Huang, 2013; Stock, Six, \& Zacharias, 2013).

This research aims to explore the effect of culture and transparency, as drivers of innovation attractiveness, on global R\&D intensity. Although the multiple contradictory views (Blodgett, Bakir, \& Rose, 2008; Fang, 2003; Venaik \& Brewer, 2013) on the Hofstede's cultural dimensions (Hofstede, Hofstede, \& Minkov, 2010), we aim to evidence whether those culture dimensions and 
transparency influence the R\&D expenditures intensity (business enterprise and public disbursements) stated out by the European countries. Our preliminary assumption states that culture influences R\&D expenditures policies, which act as subsequent drivers of knowledge assets development, impacting on potential economic returns.

\section{Theoretical background}

\section{Innovation, culture and transparency}

Culture is broadly incorporated in the society and economy as an embodiment of ideas, customs, and social behavior of a particular people, group, nation, or region. It is associated to the collective programming of mind which enables people and society to distinguish the members of one group or category of people from those of another (Hofstede et al., 2010). It is also linked to knowledge and learning (Davenport \& Prusak, 1998; Skerlavaj et al., 2013), it is also associated to values, to norms and artifacts (Stock et al., 2013). Hence, culture can be seen as a set of beliefs that drives the human action to innovativeness and, over the centuries, have driven individuals and groups to the most complex networking systems. According to Kleinschmidt, De Bretain, and Salomo (2007), corporate culture offers to companies and countries the opportunity to embrace the spirit of innovativeness and become innovative oriented. Stock et al. (2013) found that cultural artifacts fully mediate the effects of innovation-orientated value and norms on innovativeness. Thus, values and norms need to transform into specific artifacts before they can influence innovation outcomes (e.g. intellectual capital, embodied by patents, by new products, new processes, etc.). Furthermore, those authors also revealed that a company's innovation-oriented culture is less crucial in markets in which customer preferences change dramatically, however prevailing in technologically turbulent environments. The importance of culture rises in dynamic markets but decreases in markets with technological turbulence.

Linking the national and corporate levels, Skerlavaj et al. (2013) have examined the effects of culture on three key elements in the development of organizational learning: information acquisition, information interpretation, and behavioral and cognitive changes. They suggest that national culture plays an insignificant role in moderating the flows of information acquisition and interpretation. Indeed, at a corporate level, the information acquisition and interpretation seems to be associated to organizational structures, absorptive capacity of individuals and groups, and nature of knowledge to be incorporated and used. These achievements are contradictory to the evidences provided by Ambos and Schlegelmich (2008) on the scope of capability exploiting laboratories. These laboratories perform significantly better in culturally favorable environments. Thus, R\&D managers of multinational corporations should give to national culture, a more prominent role in deciding where to locate an overseas R\&D laboratory. Hence, all the contradictory outcomes provided by literature should be contextualized and analyzed at a regional level. It seems that traditional cultural values can act as enablers or detractors to innovative based actions, and strategies. These peculiar cultural factors, including national transparency perception, significantly influence the development of the entire innovation cycle, both at a national and corporate level (VanderPal, 2015; Rujirawanich, Addison, \& Smallman, 2011).

Public Sector Transparency Index (PSTI) embodies the corruption perceptions worldwide; it is measured with a score between 0 and 100, and is published by Transparency International (TI, 2016) on a yearly basis. As stated in the latest report (TI, 2016) "A poor score is likely a sign of widespread bribery, lack of punishment for corruption and public institutions that don't respond to citizen's needs". Thus, it affects the development, the integration in the sustainable 
networks, the innovation based strategies, the national welfare, and the innovative attractiveness. Transparency is associated to national culture, in particular to uncertainty avoidance (Hofstede et al., 2010) because this phenomenon affects the functioning of the state, and sometimes also of private organizations. In fact, transparency can act as an additional pillar which affects the attractiveness of institutions and policy makers. Hence, culture and transparency, as a set of individual and collective beliefs, norms, and actions, or as a collective mental programming (Hofstede et al., 2010), are expected to change very slowly over time, requiring an incremental mindset. Over decades, most countries have been characterized and have been oriented by the same set of values. However, it is unquestionable that the above mentioned set of beliefs affects national and corporate strategies, driving nations across innovation wages in a more incremental or radical way.

\section{The Hofstede's cultural dimensions}

One of the most known, and controversial, approaches on cultural differences between countries is based on the Hofstede's cultural model (Hofstede, 2001; Hofstede et al., 2010). In a first stage, he has argued that those differences have four dimensions: power distance, avoidance of uncertainty, individualism versus collectivism, and masculinity versus femininity. Subsequently, that model has incorporated two further dimensions: long-term versus short-term orientation and indulgence. Broadly, power distance expresses the extent to which less powerful members of organizations accept that power is unequally distributed (degree of inequality in society), while uncertainty avoidance embodies the extent to which people feel threatened by ambiguous situations and create beliefs and institutions by which they try to avoid them. The fundamental issue is how society deals with the fact that the future cannot be known. Individualism embodies the degree to which individuals are integrated into groups. On the other hand, masculinity refers to the distribution of emotional roles between the genders, which is another fundamental issue for any society where a range of solutions are sought; and long-term orientation promotes pragmatic virtues oriented toward future rewards, in particular thrift, persistence, and adapting to change. Finally, indulgence stands for a society that allows relatively free gratification of basic and natural human drives related to leisure. Restraint indicates a society that suppresses gratification of needs, and regulates it, by means of strict social norms.

Several researches have been carried out over the last decades, based on the Hofstede's cultural dimensions (Blodgett et al., 2008; De Mooij, 2013; Kim \& Kim, 2010; Minkov \& Hofstede, 2011; Tang \& Koveos, 2008; Venaik \& Brewer, 2013). However, the doctrine embedded by those cultural dimensions is not unanimous among authors. Minkov and Hofstede (2011) reinforce that their scientific philosophy has a moderate form of operationalization (interdependence of human minds and networks), that there is no one best way of constructing dimensions and that merit of models and dimensions depend on what researchers seek to explain (in the context of the several disciplines and approaches). In contraposition, Venaik and Brewer (2013), and Fang (2003), tried to demonstrate the irrelevance of those cultural dimensions in the context of management theory and practice. Based on the lack of scales validity, they argue that the items used to measure those dimensions are not positively and significantly correlated at the individual or organizational level and therefore do not measure, culturally, an individual, organization, or nation. In this scope, Blodgett et al. (2008) and Fang (2003) provide that Hofstede's cultural instrument lacks sufficient construct validity when applied at an individual or organizational level; however, an uncoherent structure was achieved relating the reliability of the traditional four dimensions, in particular at an individual consumer level. At a macroeconomic level, Tang and 
Koveos (2008) found that individualism, power distance, and long-term orientation demonstrate a significant curvilinear relationship with Gross Domestic Product (GDP) per capita, tending to change over time. Thus, other macroeconomic variables based on R\&D outcomes (based on innovation, science, and knowledge) should be included in the theoretical constructs. In fact, the shift of social norms reflects the changes in the attitudes shared by most people within a society, subsequently affecting the cultural standards and innovative orientations. Although the contradictory overviews and approaches on the Hofstede's cultural dimensions (Fang, 2003), it seems unquestionable that societies, organizations, and individuals, are driven by multiple and complex pillars which can enable or detract the overall innovativeness. Hence, Culture and Transparency are used, in the scope of this research, as drivers of innovation attractiveness.

\section{Analytical framework}

The current research involves 31 European countries (Appendix) and has the main objective to explore the linkage between culture, transparency and R\&D intensity, over the period 2010-2014. It follows an exploratory mainstream approach, in the scope of a phenomenon characterized by objectivity, realism, functionalism and social change (Lopes, 2015). Data was collected from several sources such as Eurostat (2016), TI (2016), and Hofstede et al. (2010). Based on the assumption that culture (power distance; individualism; masculinity; uncertainty avoidance; longterm orientation, and indulgence), transparency (public sector level of corruption), and other macroeconomic variables (gross domestic product; venture capital; high-technology trade; and human resources employed in science and technology activities), influence R\&D decisions, the core econometric specification, using panel data, is as follows:

$$
\begin{aligned}
& \hat{R D_{i t}}=\beta_{0}+\beta_{1} P D I S_{i, t}+\beta_{2} I N D_{i, t}+\beta_{3} M A S C_{i, t}+\beta_{4} U A V O I_{i, t}+\beta_{5} L T O R_{i, t} \\
& +\beta_{6} I V D_{i, t}+\beta_{7} T_{R A N S P} P_{i, t}+\beta_{8}(G D P * V C A P)_{i, t}+\beta_{9}(\text { THTEC } * H R S T)_{i, t} \\
& +\sum_{r=1}^{5} \beta_{r} D Y_{i, t}+\varepsilon_{i, t} \\
& (i=1, \ldots, n ; t=1, \ldots, m ; r=1, . ., 5)
\end{aligned}
$$

Where:

$R D$ is the logarithm of total intramural $\mathrm{R} \& \mathrm{D}$ expenditures (business enterprise, public, and education segments), per inhabitant, for country $i$ in year $t$.

$P D I S$ is the Hofstede's cultural dimension "Power Distance" (D1) for country $i$ in year $t$.

$I N D$ is the Hofstede's cultural dimension "Individualism" (D2) for country $i$ in year $t$.

$M A S C$ is the Hofstede's cultural dimension "Masculinity" (D3) for country $i$ in year $t$.

UAVOI is the Hofstede's cultural dimension "Uncertainty Avoidance" (D4) for country $i$ in year $t$.

LTOR is the Hofstede's cultural dimension "Long Term Orientation" (D5) for country $i$ in year $t$.

IVD is the Hofstede's cultural dimension "Indulgence" (D6) for country $i$ in year $t$.

TRANSP - Public Sector Transparency score for country $i$ in year $t$, according to the "Transparency International" (2010-2014).

$G D P$ is the logarithm of total Gross Domestic Product for country $i$ in year $t$. 
$V C A P$ is the logarithm of venture capital investment for country $i$ in year $t$.

THTEC is the logarithm of total high-tech trades for country $i$ in year $t$.

$H R S T$ is the logarithm of the number of persons with tertiary education employed in science and technology for country $i$ in year $t$.

$D Y_{t}$ is the time effect over the period 2010-2014.

Variables were simultaneously introduced in the model in order to identify which ones can predict the R\&D intensity at a country level (rejection of $H_{0}: \beta_{1}=\beta_{2}=\ldots=\beta_{8}=0 ; p<\alpha$ ). Two complimentary models were regressed: Model 1 incorporates the time effects and Model 2 does not include those effects. Thus, based on the literature theoretical background, we formulate the following hypotheses:

$\mathrm{H}_{1}$ : R\&D intensity is associated to the Hofstede's cultural dimensions:

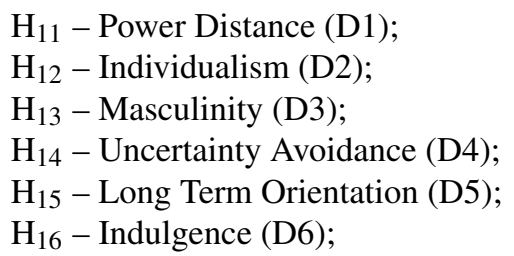

$\mathrm{H}_{2}$ : R\&D intensity is positively associated with the public sector transparency score.

$\mathrm{H}_{3}$ : R\&D intensity positively correlated with gross domestic product.

$\mathrm{H}_{4}$ : $\mathrm{R} \& \mathrm{D}$ intensity is positively associated with the intensity of venture capital investment.

$\mathrm{H}_{5}$ : $\mathrm{R} \& \mathrm{D}$ intensity is positively associated with country's total high-tech trade.

$\mathrm{H}_{6}$ : $\mathrm{R} \& \mathrm{D}$ intensity is associated with the number of persons employed in science and technology activities.

The phenomenon under analysis is complex and has multivariate causes and effects. Although the lack of literature on the linkage proposed for analysis, R\&D (IFRF, 2004) as an intermediate stage of conclusive innovation, has the power to embody a set of skills, abilities, knowledge, and expertise, toward the dynamic transformation of tacit knowledge into explicit knowledge (e.g. patents, software, alliances, rights, trademarks, technical design, etc.). Thus, our assumption is that only proactive and dynamic institutions, supported by innovative national public policies and strongly oriented to efficient knowledge transformation mechanisms, can support strong R\&D expenditures efforts (Ambos \& Schlegelmilch, 2008; Newman, 2009; Skerlavaj et al., 2013; Stock et al., 2013). In this scope, culture and transparency can act as the attractiveness drivers, for companies and individuals involved in innovative activities.

\section{Results and discussion}

Descriptive measures and association measures

The descriptive statistics for the selected sample, are included in Table 1. The bivariate correlations (Pearson's correlation coefficients) between the variables of interest are shown in Table 2. 
Table 1

Descriptive measures.

\begin{tabular}{llccrrrr}
\hline Variable & $n$ & Minimum & Maximum & Mean & Std. deviation & Skewness & Kurtosis \\
\hline RD & 155 & 3.32 & 7.31 & 5.62 & 1.21 & -0.279 & -1.195 \\
PDIS & 155 & 11 & 104 & 51.30 & 21.05 & 0.320 & -0.452 \\
IND & 155 & 25 & 80 & 58.05 & 18.17 & -0.467 & -0.835 \\
MASC & 155 & 5 & 110 & 45.32 & 23.84 & 0.150 & -0.492 \\
UAVOI & 155 & 23 & 112 & 69.39 & 21.72 & -0.536 & -0.788 \\
LTOR & 155 & 24 & 83 & 55.32 & 16.77 & -0.041 & -0.815 \\
IVD & 155 & 13 & 78 & 44.48 & 19.08 & -0.047 & -1.275 \\
TRANSP & 155 & 36 & 92 & 63.72 & 16.17 & 0.118 & -1.264 \\
GDP & 150 & 8.79 & 14.89 & 11.94 & 1.58 & 0.032 & -0.797 \\
VCAP & 145 & 0.00 & 9.96 & 4.21 & 3.24 & -0.141 & -1.367 \\
THTEC & 155 & 0.00 & 11.22 & 7.89 & 2.47 & -1.942 & 1.259 \\
HRST & 155 & 4.16 & 9.98 & 7.40 & 1.44 & -0.225 & -0.328 \\
\hline
\end{tabular}

Relating the normality, the results revealed that Skewness is in the range of $+/-1.96$ which indicates that the data are normally distributed (error variable). The same evidence was obtained for Kurtosis statistics which are distributed over the range [ $-1.367 ; 1.259]$. The Kolmogorov-Smirnov test and Shapiro-Wilk test have confirmed that variables are normally distributed for a significance level of $10 \%(p>0.1)$. Relating the homogeneity of variances, the test of Levene has failed in the rejection of null hypothesis (which states that data has no heterocedasticity problem). Thus, we have proceeded with the parametric analysis for our theoretical construct.

We also run the multicollinearity diagnosis, the residual analysis, and the heteroscedasticity. The Variance Inflation Factor (VIF) assesses the degree of multicollinearity in the model. Thus, we found that none of the independent variables of the current research has a VIF value close to 10 , concluding that the analysis does not observe a severe problem in multicollinearity. Toward analysis of independence of residuals, we used the Durbin-Watson (DW) test. Based on this statistics, we noted that a null hypothesis is rejected $\left(d<d_{\mathrm{L}}\right)$ which means that residuals cannot describe a normal distribution, confirming that those errors are positively autocorrelated. However, according Montegomery, Peck, and Vining (2001), the assumption of uncorrelated or independent errors for time series or panel data is often not appropriate because it is usual to be associated with business and economic phenomena. Relating heteroscedasticity, we used the test of White, not rejecting the null hypothesis $(p>0.05)$. Thus, the evidences provided by the current econometric model can serve as an important contribution to theory and practice.

As already mentioned, the phenomenon under analysis evidences multiple associations as illustrated by the bilateral correlations. All variables, except LTOR, THTEC, and HRST, are not significantly correlated $(p<\alpha)$ with $\mathrm{R} \& \mathrm{D}$. Thus, this primary overview confirms our assumption that culture and transparency influence $R \& D$, mostly with the expected signals. THTEC is not associated with $\mathrm{R} \& \mathrm{D}(r=-0.036 ; p=0.659)$, confirming that there is no bilateral direct association between $R \& D$ and high-technology trade. This evidence corroborates the outcomes provided by Chan et al. (2003) that there is no correlation between R\&D expenditures and turnover derived from innovation. The human resources employed in science and technology seems to be an important driver of innovation, however not directly influencing the $R \& D$ expenditures and strategies.

As developed and argued by Hofstede et al. (2010), the six cultural dimensions are not independent which can be confirmed by the associations between them in the table above. The human 
Table 2

Pearson's correlation coefficients.

\begin{tabular}{|c|c|c|c|c|c|c|c|c|c|c|c|c|}
\hline VAR. & $\mathrm{RD}$ & PDIS & IND & MASC & UAVOI & LTOR & IVD & TRANSP & GDP & VCAP & THTEC & HRST \\
\hline RD & 1 & & & & & & & & & & & \\
\hline PDIS & $-0.701^{* * * *}$ & 1 & & & & & & & & & & \\
\hline IND & $0.582^{* * *}$ & $-0.628^{* * * *}$ & 1 & & & & & & & & & \\
\hline MASC & $-0.147^{*}$ & $0.252^{* * *}$ & 0.036 & 1 & & & & & & & & \\
\hline UAVOI & $-0.520^{* * * *}$ & $0.641^{* * * *}$ & $-0.602^{* * * *}$ & $0.194^{* *}$ & 1 & & & & & & & \\
\hline LTOR & -0.121 & $0.188^{* *}$ & 0.117 & 0.145 & 0.133 & 1 & & & & & & \\
\hline IVD & $0.729^{* * * *}$ & $-0.549^{* * * *}$ & $0.430^{* * * *}$ & -0.092 & $-0.474^{* * * *}$ & $-0.444^{* * * *}$ & 1 & & & & & \\
\hline TRANSP & $0.882^{* * *}$ & $-0.679^{* * *}$ & $0.570^{* * * *}$ & $-0.362^{* * * *}$ & $-0.578^{* * *}$ & $-0.146^{*}$ & $0.678^{* * * *}$ & 1 & & & & \\
\hline GDP & $0.369^{* * * *}$ & $-0.190^{* * *}$ & $0.390^{* * * *}$ & $0.173^{* *}$ & -0.134 & -0.023 & $0.274^{* * * *}$ & $0.311^{* * * *}$ & 1 & & & \\
\hline VCAP & $0.542^{* * * *}$ & $-0.293^{* * * *}$ & $0.454^{* * * *}$ & -0.009 & $-0.164^{* *}$ & -0.137 & $0.405^{* * * *}$ & $0.537^{* * * *}$ & $0.891^{* * * *}$ & 1 & & \\
\hline THTEC & -0.036 & -0.036 & 0.135 & $0.372^{* * *}$ & 0.118 & $0.302^{* * * *}$ & -0.025 & -0.052 & $0.605^{* * * *}$ & $0.480^{* * * *}$ & 1 & \\
\hline HRST & 0.094 & -0.018 & $0.247^{* * * *}$ & $0.205^{* *}$ & -0.006 & 0.074 & 0.039 & 0.039 & $0.945^{* * * *}$ & $0.776^{* * * *}$ & $0.682^{* * * *}$ & 1 \\
\hline
\end{tabular}

${ }^{*} p<0.1$.

${ }^{* *} p<0.05$.

**** $p<0.01$ 
Table 3

Regression model equations.

\begin{tabular}{|c|c|c|c|c|c|c|}
\hline & \multicolumn{3}{|c|}{ Model 1} & \multicolumn{3}{|c|}{ Model 2} \\
\hline & $\beta$ & $t$ & VIF & $\beta$ & $t$ & VIF \\
\hline Intercept & 3.203 & $4.688^{* * * *}$ & & 3.164 & $4.771^{\text {**** }}$ & \\
\hline PDIS & -0.032 & $-6.340^{* * *}$ & 1.003 & -0.032 & $-6.394^{* * *}$ & 1.045 \\
\hline IND & 0.007 & 1.555 & 2.342 & 0.008 & 1.607 & 2.340 \\
\hline MASC & -0.006 & $-1.848^{*}$ & 2.784 & -0.006 & $-1.886^{*}$ & 2.783 \\
\hline UAVOI & 0.018 & $4.271^{* * *}$ & 2.683 & 0.018 & $4.340^{* * * *}$ & 2.674 \\
\hline LTOR & 0.010 & $2.993^{* * * *}$ & 1.460 & 0.010 & $2.963^{\text {**** }}$ & 1.454 \\
\hline IVD & 0.016 & $2.718^{* * * *}$ & 2.567 & 0.015 & $2.701^{* * * *}$ & 2.545 \\
\hline TRANSP & 0.022 & $3.214^{* * * *}$ & 2.629 & 0.023 & $3.474^{* * * *}$ & 2.508 \\
\hline GDP*VCAP & 0.010 & $2.356^{* *}$ & 1.921 & 0.009 & $2.230^{* *}$ & 1.653 \\
\hline THTEC*HRST & -0.009 & -1.346 & 1.775 & -0.008 & -1.176 & 1.537 \\
\hline \multirow[t]{5}{*}{ Time effects } & & & Yes & & No & \\
\hline & $\operatorname{Adj} . R^{2}=$ & & 0.858 & & 0.861 & \\
\hline & $F=$ & & 44.980 & & 66.427 & \\
\hline & Sig. & & $<0.001$ & & $<0.001$ & \\
\hline & $D W$ & & 1.633 & & 1.542 & \\
\hline
\end{tabular}

${ }^{*} p<0.1$.

** $p<0.05$.

*** $p<0.01$.

nature is the basis of mental programming, crossing all cultural pillars. The other variables are also correlated in many cases, identifying a wide set of phenomena which require further exploration and discussion in forthcoming and complimentary researches.

\section{The regression models}

This section contains the multivariate regression results (combined impact on R\&D) for both models: model 1 embodying the time effects and model 2 not incorporating those effects. Both models evidence a high adherence level $(F=63.914$ and $F=89.895 ; p<0.001$, for Model 1 and model 2, respectively) and the variance of R\&D is explained in approximately $86 \%$. Comparing the two models used, we did not find any significant time effects, confirming that the phenomenon under analysis is culturally and economically driven and focused on long term strategies and policies. The regression equations are indicated below (Table 3).

As expected, PDIS $\left(\beta_{1}=-0.032 ; p<0.001\right)$ influences negatively the R\&D. The higher power distance, the less the $R \& D$ expenditures and innovation based strategies. Literature (Hofstede et al., 2010) also supports the positive impact of IND, UAVOI, LTOR and IVD on R\&D. In fact, these expenditures are long-term oriented, levering the more complex innovation based chain "Culture $-R \& D$ - Intangibles - Economic Benefits" into a company or national sustainability level (VanderPal, 2015). Indulgence is associated with well-educated populations, more extroverted personalities, positive attitude, among other attributes. Based on these theoretical concerns, it was expectable a positive impact on R\&D strategy, in line with its long term orientation. Relating masculinity, we found a low significance level, in particular in the model with time effects. The hybrid nature of this dimension can support the results achieved $\left(\beta_{3}=-0.006 ; p=0.067\right)$. We have to underline that MASC is bilaterally associated to HRST $(r=0.205 ; p=0.011)$, 


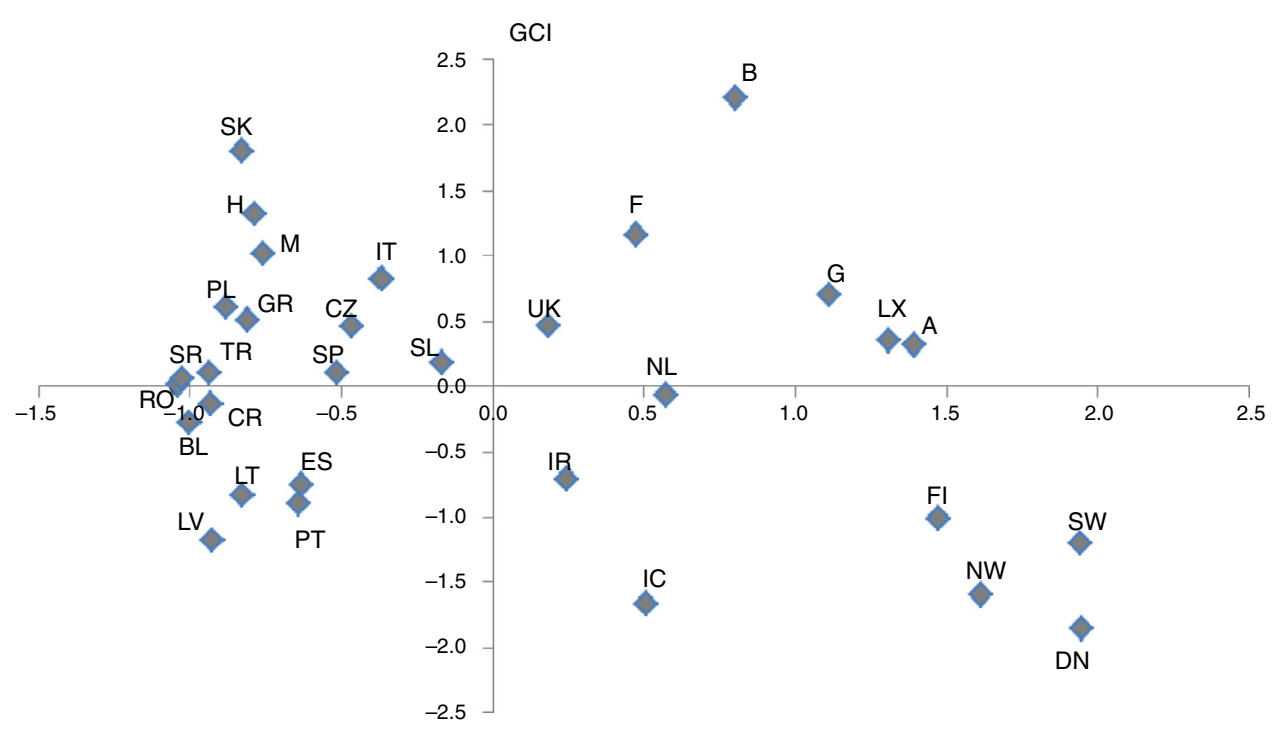

Fig. 1. Culture and R\&D across Europe.

variable without significant impact on $\mathrm{R} \& \mathrm{D}$ expenditures. Thus, $\mathrm{H}_{1}$, including the sub hypotheses, is not rejected, which means that R\&D intensity is influenced by the Hofstede's cultural dimensions.

TRANSP emerges in the current research as a novelty. Our assumption is that public sector corruption is also embedded in culture, affecting the innovation decisions and strategies and the attractiveness power of individuals and organizations. Our assumption was confirmed through the bilateral correlations and through the combined effect in both models $\left(\beta_{7}=0.022\right.$ and $\beta_{7}=0.023 ; p<0.001$, for model 1 and model 2 , respectively). The high transparency score, the high $\mathrm{R} \& \mathrm{D}$ intensity per inhabitant. Thus, $\mathrm{H}_{2}$ cannot be rejected.

The combined effect of GDP and VCAP is positive and significantly associated with R\&D $(p<0.001)$. The value creation derived from uncertain and risky environments has a leveraging impact on innovation. Not surprisingly, our $\mathrm{H}_{3}$ and $\mathrm{H}_{4}$ cannot be rejected which confirm the traditional economic literature. Finally, we found a negative impact from the conjoint effect of THTEC and HRST $\left(\beta_{9}=-0.009\right.$ and $\beta_{9}=-0.008 ; p<0.001$, for model 1 and model 2, respectively) on R\&D expenditures. Without literature support, it seems that countries at a consolidate stage of development (with higher rates of high technology trade and higher level of science and technology employment) tend to reduce their levels of R\&D expenditures. This assumption does not support the literature concerning the dynamism and sustainability of the innovation cycles. Despite the statistical significance, the sign of our hypothesis $\mathrm{H}_{5}$ and $\mathrm{H}_{6}$ is not confirmed.

\section{The integrated overview between culture and $R \& D$}

The Global Culture Index (GCI) is a non-weighted index based on the six Hofstede's cultural dimensions and aims to provide an integrated overview across Europe, based on two social and economics pillars: Culture and R\&D.

The influence of culture on R\&D intensity does not seem to be a geographical issue. Based on the evidences provided in Fig. 1, we cannot identify specific geographical clusters, except 
in the cluster of Nordic countries and the cluster of Central Europe countries. In this case, we observe higher levels of GCI and R\&D efforts than in Europe's peripheral regions. The R\&D intensity is influenced by culture dimensions, however driven by social, political, and economic factors.

\section{Concluding remarks and directions}

Culture and transparency embody a set of human beliefs, norms and actions, individual and collectively observed which drive organizations into a certain level of development and economic welfare. Those pillars are the basis of the innovation chain toward the dynamic transformation of knowledge. R\&D is, in our approach and assumptions, a link in that chain, enabling or detracting the recognition of intangibles and subsequent future economic benefits. Without time effects, our econometric model provided evidences on the impact of Hofstede's cultural dimensions, the public sector transparency index, and other macroeconomic variables, on R\&D expenditures efforts. Thus, we underline the following remarks and potential future directions:

- All cultural dimensions are significantly correlated with R\&D expenditures, however not geographically clustered. As expected, "Power Distance" has a negative impact while "Individualism", "Uncertainty Avoidance", "Long-Term Orientation", and "Indulgence" have a positive signal. Although the negative signal, "Masculinity" has a residual significance in our econometric model. These cultural dimension scores were extracted form Hofstede et al. (2010) and have been, over the last decades, being questioned about their validity and robustness (Fang, 2003; Venaik \& Brewer, 2013). Its application should be discussed and balanced in each particular scope and scientific field.

- The corruption of a country level is bilaterally linked with culture and has a positive and significant impact on R\&D national strategies. Thus, the high transparency level for the country, the high R\&D expenditures per inhabitant. The Public Sector Transparency Index is published by an independent organization on a yearly basis. As secondary data, this score can be biased by methodological issues which can also bias the current outcomes.

- The value creation derived from uncertain and risky environments has a leveraging impact on innovation, supporting the positive impact of gross domestic product and venture capital investment on R\&D expenditures. Surprisingly, countries with a consolidated stage of development (with higher rates of high technology trade and higher level of science and technology employment) tend to reduce their levels of R\&D intensity.

The empirical results provide both an understanding of how cultural dimensions and transparency affect the level or $R \& D$ expenditures at a country level. The research adds value to the current literature by introducing in an econometric model the six Hofstede's cultural dimensions and, as a novelty, the public sector transparency index provided by an independent organization. Extending both the number of countries under analysis could corroborate or refute the evidence achieved in the current research. In the future, research may be directed into a more precise identification of clusters and into the exploration of certain particular national policies on innovation. Other methodological approaches, such as a simultaneousequations model or generalized method of moments, can be used toward more robust and accurate outcomes. 


\section{Appendix - list of countries.}

1. B-Belgium

2. BL - Bulgaria

3. $\mathrm{CZ}-\mathrm{Czech}$ Republic

4. DN - Denmark

5. G-Germany

6. ES - Estonia

7. IR - Ireland

8. GR - Greece

9. SP - Spain

10. F- France

11. CR - Croatia

12. IT - Italy

13. LV - Latvia

14. LT - Lithuania

15. LX - Luxembourg

16. $\mathrm{H}-$ Hungary

17. M - Malta

18. NL - Netherlands

19. A - Austria

20. PL - Poland

21. PT - Portugal

22. RO - Romania

23. SL - Slovenia

24. SK - Slovakia

25. FI - Finland

26. SW-Sweden

27. UK - United Kingdom

28. IC - Iceland

29. NW - Norway

30. SR - Serbia

31. TR - Turkey

\section{References}

Akinwale, Y. O., Dada, A. D., Oluwadare, A. J., Jesuleye, O. A., \& Siyanbola, W. O. (2012). Understanding the nexus of R\&D. Innovation and economic growth in Nigeria. International Business Research, 5(11), 187-196, http://doi.org/10.5539/ibr.v5n11p187

Ambos, B., \& Schlegelmilch, B. B. (2008). Innovation in multinational firms: Does cultural fit enhance performance? Management International Review, 48(2), 189-206, http://doi.org/10.1007/s11575-008-0011-2

Blodgett, J. G., Bakir, A., \& Rose, G. M. (2008). A test of the validity of Hofstede's cultural framework. Journal of Consumer Marketing, 25(6), 339-349, http://doi.org/10.1108/07363760810902477

Chan, L. K. C., Lakonishok, J., \& Sougiannis, T. (2003). The stock market valuation of research and development expenditures. In John Hand, \& Baruch Lev (Eds.), Intangible assets: Values, measures and risks (pp. 387-414). Oxford: Oxford University Press.

Chen, C., Hu, J., \& Yang, C. (2011). An international comparison of R\&D efficiency of multiple innovative outputs: The role of the national innovation system. Innovation: Management, Policy \& Practice, 13(1), 341-360, http://doi.org/10.5172/impp.2011.13.3.341 
Davenport, T., \& Prusak, L. (1998). Working knowledge - How organisations manage what they know. Boston, MA: Harvard Business School Press.

Deschryvere, M. (2014). R\&D, firm growth and the role of innovation persistence: An analysis of Finnish SMEs and large firms. Small Business Economics, 43(1), 767-785, http://doi.org/10.1007/s11187-014-9559-3

Eurostat. (2016). European statistics. Available at http://ec.europa.eu/eurostat/data. Accessed 16.05.16

Fernández-Jardón, C., Costa, R. V., \& Dorregio, P. F. (2014). The impact f structural capital on product innovation performance: An empirical analysis. International Journal of Knowledge-Based Development, 5(1), 63-79, http://doi.org/10.1504/IJKBD.2014.059799

Fang, T. (2003). A critique of Hofstede's fifth national culture dimension. International Journal of Cross Cultural Management, 3(3), 347-368, http://doi.org/10.1177/1470595803003003006

Fontana, R., Nuvolari, A., Shimizu, H., \& Vezzulli, A. (2012). Schumpeterian patterns of innovation and the sources of breakthrough inventions: Evidence from a data-set of R\&D awards. Journal of Evolutionary Economics, 22(1), 785-810, http://doi.org/10.1007/s00191-012-0287-z

Hofstede, G. (2001). Culture's consequences. In Comparing values, behaviours, institutions and organizations across nations (2nd ed.). Thousand Oaks, CA: Sage Publications.

Hofstede, G., Hofstede, G. J., \& Minkov, M. (2010). Cultures and organizations. In Software of the mind. Revised and expanded (3rd ed.). New York: McGraw-Hill.

IFRF - International Financial Reporting Foundation (2004). International accounting standard no. 38: Intangible assets. Available at http://www.ifrs.org/IFRSs/Pages/IFRS.aspx. [accessed 10.05.16]

Jewkes, J., Sawers, D., \& Stillerman, R. (1958). The sources of invention. Revised edition 1969. London: MacMillan.

Kim, Y., \& Kim, S. (2010). The influence of cultural values on perceptions of corporate social responsibility: Application of Hofstede's dimensions to Korean public relations practitioners. Journal of Business Ethics, 91(1), 485-500, http://doi.org/10.1007/s10551-009-0095-Z

Kleinschmidt, E. J., De Bretain, U., \& Salomo, S. (2007). Performance of global new product development programs: A resource based view. Journal of Product Innovation Management, 24(5), 419-441, http://doi.org/10.1111/j.15405885.2007.00261.x

Lev, B., \& Sougiannis, T. (1996). The capitalization, amortization, and value-relevance of R\&D. Journal of Accounting and Economics, 21(1), 107-138, http://doi.org/10.1016/0165-4101(95)00410-6

Lopes, I. T. (2015). Research methods and methodology towards knowledge creation in accounting. Contaduría y Administración, 60(S1), 9-30, http://doi.org/10.1016/j.cya.2015.08.006

Malerba, F. (2005). Sectorial systems: How and why innovation differs across sectors. In J. Fagerberg, \& D. C. Mowery (Eds.), The Oxford handbook of innovation (pp. 380-406). Oxford: Oxford University Press.

Malerba, F., \& Orseningo, L. (1995). Schumpeterian patterns of innovation. Cambridge Journal of Economics, 19(1), 47-65, http://doi.org/10.1093/oxfordjournals.cje.a035308

Malerba, F., \& Orseningo, L. (1996). Schumpeterian patterns of innovation are technology-specific. Research Policy, 25(1), 451-478, http://dx.doi.10.1016/0048-7333(95)00840-3

Minkov, M., \& Hofstede, G. (2011). The evolution of Hofstede's doctrine. Cross Cultural Management: An International Journal, 18(1), 10-20, http://doi.org/10.1108/13527601111104269

Montegomery, D. C., Peck, E. A., \& Vining, G. G. (2001). Introduction to linear regression analysis (3rd ed.). New York: John Wiley \& Sons.

Pavitt, K. (1984). Patterns of technical change: Towards a taxonomy and a theory. Research Policy, 13(1), 343-373, http://doi.org/10.1016/0048-7333(84)90018-0

Newman, J. L. (2009, September-October). Building a creative high-performance R\&D culture. Research Technology Management, 21-31.

Rujirawanich, P., Addison, R., \& Smallman, C. (2011). The effects of cultural factors on innovation in a Thai SME. Management Research Review, 34(12), 1264-1279, http://doi.org/10.1108/01409171111186397

Skerlavaj, M., Su, C., \& Huang, M. (2013). The moderating effects of national culture on the development of organizational learning culture: A multilevel study across seven countries. Journal of East European Management Studies, 18(1), 97-134.

Stock, R. M., Six, B., \& Zacharias, N. (2013). Linking multiple layers of innovation-oriented corporate culture, product program innovativeness, and business performance: A contingency approach. Journal of the Academy of Marketing Science, 41(1), 283-299, http://doi.org/10.1007/s11747-012-0306-5

Tahinakis, P., \& Samarinas, M. (2013). R\&D expenditures and investors' perception for an input on innovation creation and firm growth: Empirical evidence from Athens stock exchange. The Journal of Applied Business Research, 29(1), 125-137. 
Tang, L., \& Koveos, P. E. (2008). A framework to update Hofstede's cultural value indices: Economic dynamics and institutional stability. Journal of International Business Studies, 39(1), 1045-1063, http://doi.org/ 10.1057/palgrave.jibs.8400399

TI - Transparency International. (2016). Corruption perceptions. Available at http://www.transparency.org. [accessed 28.03.16]

VanderPal, G. A. (2015). Impact of R\&D expenses and corporate financial performance. Journal of Accounting and Finance, 15(7), 135-149.

Venaik, S., \& Brewer, P. (2013). Critical issues in the Hofstede and GLOBE national culture models. International Marketing Review, 30(5), 469-482, http://doi.org/10.1108/IMR-03-2013-0058 